\title{
The Structure of Catalyst Layers and Cell Performance in Proton Exchange Membrane Fuel Cells*
}

\author{
Hiroyuki INOUE**, Hirofumi DAIGUJI** and Eiji HIHARA**
}

\begin{abstract}
A catalyst layer is one of the key elements in polymer electrolyte membrane fuel cells (PEMFC). Improvements in the performance of a membrane electrode assembly (MEA) for PEMFC are much influenced by an electrochemically active surface area in a catalyst layer. But the relation between the structure of a catalyst layer and the cell performance has not been clarified yet. In the present study, catalyst layers with different structure and composition were fabricated, and the structural properties of catalyst layers, such as thickness and roughness, and the polarization curves were measured. The experimental results suggested that there is an optimum mass ratio of electrolyte in a catalyst layer for the cell performance, and the thickness and roughness of a catalyst layer change significantly at the optimum mass ratio.
\end{abstract}

Key Words: Fuel Cell, Cell Performance, Catalyst Layer, Electrolyte, AFM Imaging

\section{Introduction}

A catalyst layer is one of the key elements in PEMFC. Improvements in the performance of MEA for PEMFC are much affected by an electrochemically active surface area in a catalyst layer. A reaction of PEMFC occurs on the platinum (Pt) particle surface covered with electrolyte. A catalyst site must satisfy three criteria for it to contribute to the electrochemical reaction in a fuel cell. The criteria are proton access, gas access, and electronic path continuity. The structure and composition of an electrode can affect all three of these parameters in varying degrees. To maximize catalyst utilization, it is desirable to satisfy these three criteria for as many of catalyst sites as possible. But the transports of proton, reactant gases and electron in a catalyst layer are still to be solved, and it is important to clarify the relation between the structure of a catalyst layer and the cell performance.

Electrodes with very high Pt loading $\left(4 \mathrm{mg} / \mathrm{cm}^{2}\right)$ were previously used to achieve high power density because an electrochemically active surface area in PEMFC is only Pt surface between the solid electrolyte membrane and the solid electrode. Subsequently, Pt supported on carbon

* Received 30th July, 2003 (No. 03-4180)

** Institute of Environmental Studies, Graduate Student of Frontier Sciences, The University of Tokyo, 7-3-1 Hongo, Bunkyo-ku, Tokyo 113-0033, Japan.

E-mail: daiguji@k.u-tokyo.ac.jp
(Pt/C) was used instead of Pt black (Pt particle) to reduce the Pt loading. But it was still necessary to increase an electrochemically active surface area. In the mid $1980 \mathrm{~s}$, the ingenious method was developed by Ticianelli et al. ${ }^{(1)}$ This method involved the impregnation of the perfluorosulfonic ionomer Nafion (DuPont) into a porous gas diffusion electrode. The purpose of this method was to extend the electrochemically active surface area into the catalyst layer, and Pt loading was reduced to one-tenth retaining the cell performance. More recently, to increase the catalyst utilization further, a new method was developed by Wilson et al. ${ }^{(2)}$ The perfluorosulfonic ionimer Nafion solution was added into catalyst ink beforehand and a film of catalyst layer was hot-pressed onto an electrolyte membrane. In this method (the decal method), the perfluorosulfonic ionomer Nafion acts as a proton conductor and a binder in an electrode, and low Pt loading $\left(0.2 \mathrm{mg} / \mathrm{cm}^{2}\right)$ could be realized.

It has been already known that the polarization curves depend on the mass ratio of electrolyte in a catalyst layer in the impregnation $\operatorname{method}^{(3)}$ and the decal method ${ }^{(4),(5)}$. But the relation between the structure and composition of a catalyst layer and the cell performance has not been clarified yet. In the present study, catalyst layers with different compositions were fabricated in the method proposed by Wilson et al. ${ }^{(2)}$ The mass of $\mathrm{Pt}$ in a catalyst layer ranged from 0.04 to $0.26 \mathrm{mg} / \mathrm{cm}^{2}$, and the mass ratio of electrolyte in a catalyst layer ranged from 10 to $40 \mathrm{wt} \%$. For 
MEAs fabricated here, the current-voltage characteristics were measured. In addition, the thickness and roughness of catalyst layers were measured with a micrometer and an atomic force microscope (AFM), respectively. The relation between the structure of a catalyst layer and the cell performance was discussed.

\section{Experimental Methods}

\subsection{Chemicals and MEA fabrication}

MEA was fabricated in the method proposed by Wilson et al. ${ }^{(2)}$ The protocol in detail was as follows:

1. Combine $\mathrm{Pt} / \mathrm{C}$ catalyst and electrolyte solution. $\mathrm{Pt} / \mathrm{C}$ catalysts are TEC10V30E (Tanaka Kikinzoku Kogyo), consisting of $30 \%$ platinum on Vulcan XC-72R carbon powder (Cabot Corp.), and TEC10V50E, 50\% platinum on Vulcan XC-72R carbon powder, and the electrolyte solution is Aciplex SS-910 (Asahi Kasei Co.), $5 \mathrm{wt} \%$ Aciplex solution.

2. Add water and glycerol such that the mass ratios are about $1: 5: 20$ for carbon/water/glycerol. Mix and ultrasound extensively this solution (ink).

3. A blank of Teflon (DuPont) film of $0.1 \mathrm{~mm}$ in thickness is painted with a layer of the ink and baked in a forced convection oven at $403 \mathrm{~K}$ until dry.

4. A polymer electrolyte membrane, Aciplex S-1002 (Asahi Kasei Co.) is sandwiched between two PTFE films with catalyst layers and these are hot-pressed together at $403 \mathrm{~K}$ and $9.8 \mathrm{MPa}$ for 90 second.

5. MEA is removed from the press and allowed to cool, and then only Teflon blank is peeled away from MEA, leaving the thin film adhering to the membrane.

Parameters were the overall mass and composition of a catalyst layer. The overall mass of a catalyst layer ranged from 0 to $1.34 \mathrm{mg} / \mathrm{cm}^{2}$, it was calculated from the mass difference between a Teflon film and the file with a catalyst layer. The mass ratio of electrolyte in a catalyst layer ranged from $10 \mathrm{wt} \%$ to $50 \mathrm{wt} \%$.

\subsection{Cell performance experiment}

The polarization curves were measured using a single cell of $3 \mathrm{~cm} \times 3 \mathrm{~cm}$ in the active electrode area. Figure 1 shows the schematic diagram of the single cell. A serpentine channel was formed on the surface of separators. The channels were $0.5 \mathrm{~mm}$ deep and $2 \mathrm{~mm}$ wide at an interval of $2 \mathrm{~mm}$. The carbon/PTFE layer, CARBEL-CFP 300 (JAPAN GORE-TEX Inc.) was used as a diffusion layer. The thickness of this paper was $0.3 \mathrm{~mm}$. Because the size of the electrolyte membrane is slightly wider than that of a catalyst layer, the surface of the electrolyte membrane without catalyst layer were covered with PTFE sheets of $0.2 \mathrm{~mm}$ in thickness to prevent gas leakage. After positioning a MEA between two PTFE sheets, two separators and two rubber sheets, the cell was fixed between stainless outer frames. Rubber sheets were used for electrical insulation and prevention of gas leakage. The cell was clamped by 12 bolt and nuts. The porosity and thickness of carbon paper depend on the clamping pressure ${ }^{(6)}$, and they affect the cell performance. In this study, torque of each bolt and nut was set to be $7 \mathrm{Nm}$.

Figure 2 shows the schematic experimental setup. The single cell was installed in a fuel cell test section where the temperature of a cell was controlled and the reactant gases in desired conditions were supplied. The reactant gases at anode and cathode sides were $\mathrm{H}_{2}$ and air, respectively. The flow rates of the reactant gases $\left(\mathrm{H}_{2} /\right.$ air $)$ were $0.5 / 1.2 \mathrm{NL} / \mathrm{min}$ (about 8 times larger than the stoichiometric flow rate at $1.0 \mathrm{~A} / \mathrm{cm}^{2}$ ). Because the aim of this experiment is to clarify the effect of the structure and composition of a catalyst layer on the cell performance, the large amount of gases should be supplied to alleviate the diffusion polarization. The reactant gases were released into atmospheric air after passing through the cell. The reactant gases were humidified by passing through water baths with an inside volume of $2 \mathrm{~L}$. The temperatures of water baths at the anode side and the cathode side were set to be 353 and $333 \mathrm{~K}$, respectively. Because water drags together with a proton moving through the membrane from the anode side to the cathode side, the temperature of a water bath at the anode side was slightly higher than that of the cathode side. The cell temperature was $353 \mathrm{~K}$ in all experiments. The current-voltage characteristics were

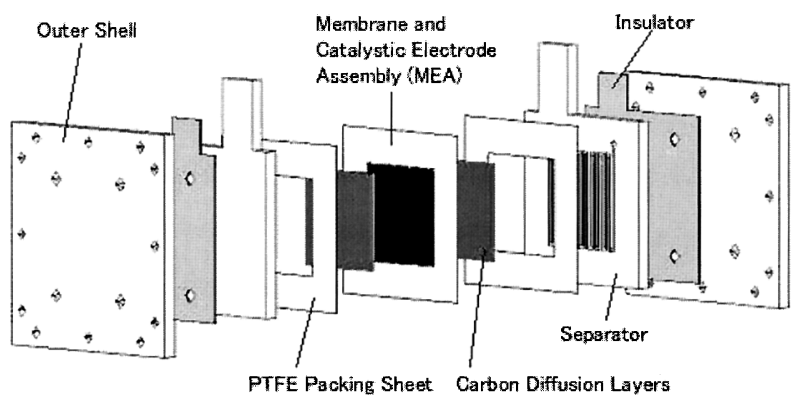

Fig. 1 Schematic diagram of a single cell

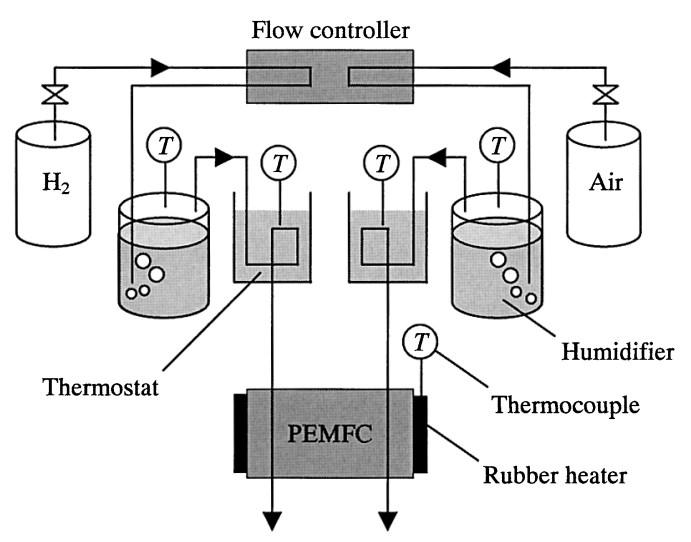

Fig. 2 Schematic experimental setup 
measured by an electronic load (Kikusui Electronics corp., model PLZ-152WA).

\subsection{Thickness measurement}

To investigate the structure and composition of a catalyst layer, the thickness of a catalyst layer was measured with a micrometer. After catalyst ink was dried in a forced convection oven, the thickness of Teflon films with and without a catalyst layer was measured at ten different places. The thickness of a catalyst layer was derived from subtracting the average thickness of a Teflon film from that of the film with a catalyst layer.

\subsection{AFM imaging}

Another way to investigate the structure and composition of catalyst layers was to measure the roughness of a catalyst layer with an AFM (Seiko Instruments Co., model Nanopics 1000). After catalyst ink was dried in a forced convection oven, the surface of a catalyst layer was measured. The surface measured here contacted with the surface of an electrolyte membrane, and they were hot pressed. The mass ratios of electrolyte in a catalyst layer were 10, 25 and $40 \mathrm{wt} \%$, and the amounts of Pt loading were $0.07,0.10,0.20$, and $0.26 \mathrm{mg} / \mathrm{cm}^{2}$. The surface of $\mathrm{Pt} / \mathrm{C}$ particles was also measured.

\section{Results}

\subsection{Cell performance experiment}

Figure 3 (a) and (b) show the effect of the overall mass of a thin film catalyst layer on the polarization curves for two different types of $\mathrm{Pt} / \mathrm{C}$ catalysts, 50\% $\mathrm{Pt}$ loading $\mathrm{Pt} / \mathrm{C}$ and 30\% $\mathrm{Pt}$ loading $\mathrm{Pt} / \mathrm{C}$, respectively. The mass ratio of electrolyte in a catalyst layer is $25 \mathrm{wt} \%$. It is noted that the mass of Pt varies together with the overall mass of a catalyst layer. In this study, the compositions of thin film catalyst layers of cathode and anode are the same, and the overall mass of a thin film catalyst layer is defined as the average mass of cathode and anode. In Fig. 3 (a) and (b), there is an optimum mass of a catalyst layer for the cell performance, and the trends of polarization curves are the same. When the mass of a catalyst layer is small, the cell voltage is small due to the shortage of $\mathrm{Pt}$, and the cell voltage increases with increasing the mass of a catalyst layer. However as the mass of a catalyst layer increases further, the cell voltage decrease. Three criteria for a catalyst site, that is, proton access, gas access, and electronic path continuity, deteriorate. Because the output signals for 30\% $\mathrm{Pt}$ loading $\mathrm{Pt} / \mathrm{C}$ were larger than those for $50 \% \mathrm{Pt}$ loading $\mathrm{Pt} / \mathrm{C}, 30 \% \mathrm{Pt}$ loading $\mathrm{Pt} / \mathrm{C}$ was used as a catalyst in the following experiments.

Figure 4 (a) and (b) show the effect of the overall mass of a catalyst layer on the polarization curves for two different mass ratios of electrolyte, 10 and $40 \mathrm{wt} \%$, respectively. The catalyst is $30 \% \mathrm{Pt}$ loading $\mathrm{Pt} / \mathrm{C}$. Figure 3 (b) is also comparable to these two graphs for the catalyst layer of $25 \mathrm{wt} \%$ electrolyte. In all three graphs, there is an op-

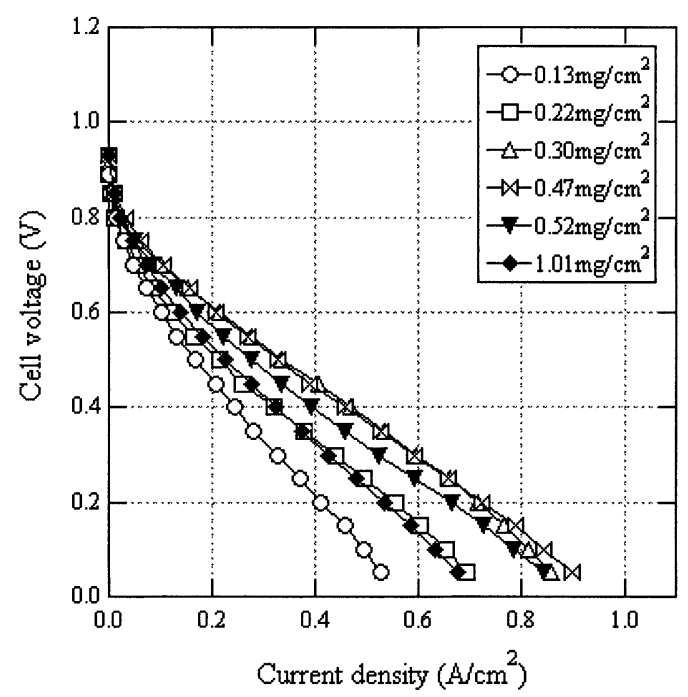

(a)

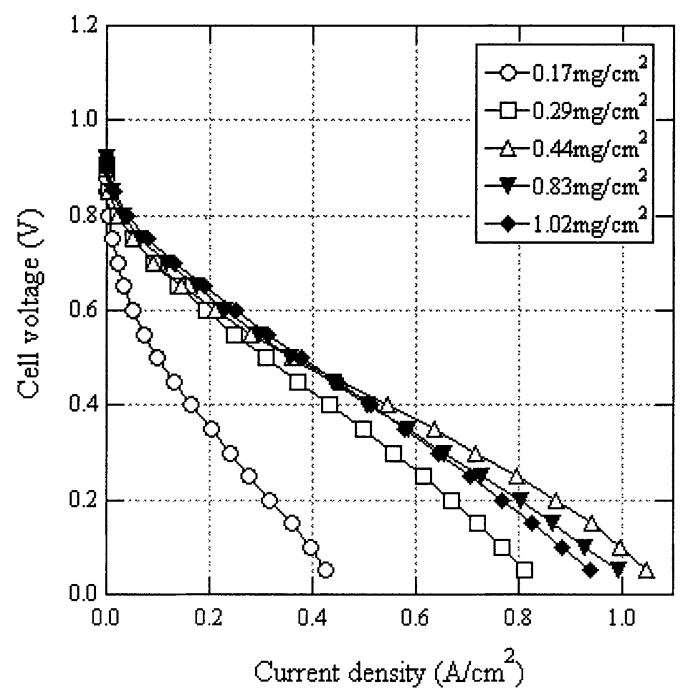

(b)

Fig. 3 Effect of the mass of a catalyst layer on polarization curves for two different types of $\mathrm{Pt} / \mathrm{C}$ catalysts, (a) 50\% $\mathrm{Pt}$ loading $\mathrm{Pt} / \mathrm{C}$, (b) $30 \% \mathrm{Pt}$ loading $\mathrm{Pt} / \mathrm{C}$. The mass ratio of electrolyte in a catalyst layer is $25 \mathrm{wt} \%$.

timum mass of a catalyst layer for the cell performance. In Fig. 3 (b), the cell voltage increases monotonically with increasing the mass of a catalyst layer in the small current density region, but in the large current density region, the maximum cell voltage can be obtained when the mass of a catalyst layer is $0.44 \mathrm{mg} / \mathrm{cm}^{2}$. The experimental result implies that in the small current density region, the total area of catalyst sites is critical for the cell performance, and in the large current density region, three criteria for a catalyst site, that is, proton access, gas access, and electronic path continuity, is more important. In Fig. 4 (b), the cell voltage decreases significantly when the amount of a catalyst layer is larger than the optimum value. The overall mass of a catalyst layer strongly affects the polarization curves 


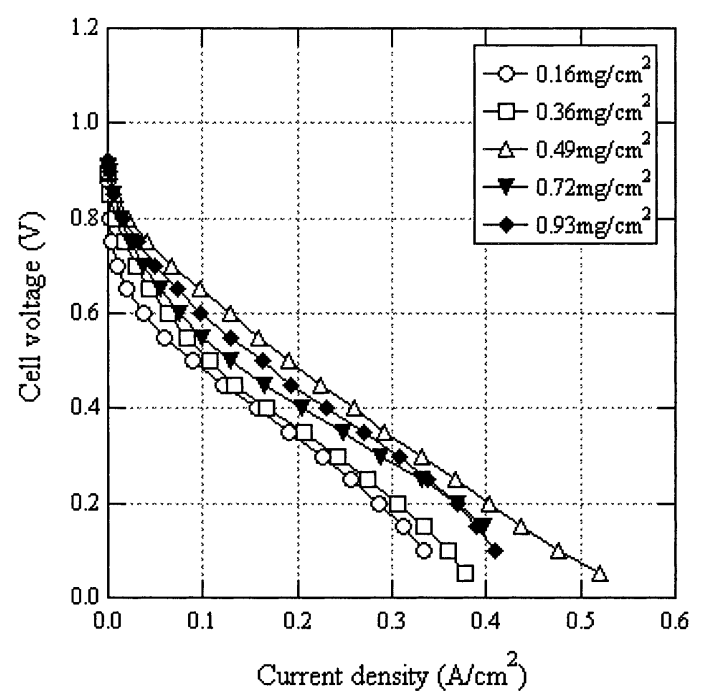

(a)

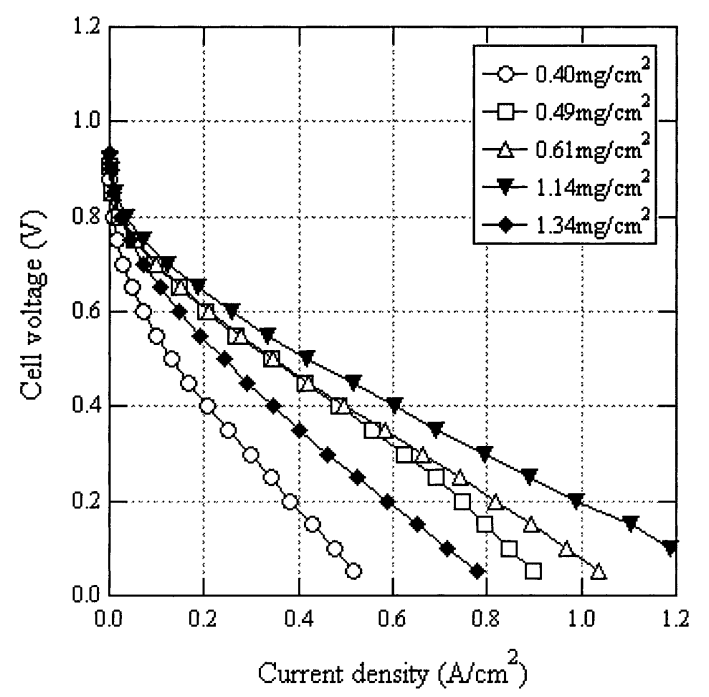

(b)

Fig. 4 Effect of the mass of a catalyst layer on the polarization curves for two different mass ratios of electrolyte, (a) $10 \mathrm{wt} \%$, (b) $40 \mathrm{wt} \%$. The catalyst is $30 \% \mathrm{Pt}$ loading $\mathrm{Pt} / \mathrm{C}$.

when the mass ratio of electrolyte is high.

Figure 5 (a) - (c) show the effect of the mass ratio of electrolyte in a catalyst layer on the cell performance for three different amounts of $\mathrm{Pt}, 0.07,0.11,0.21 \mathrm{mg} / \mathrm{cm}^{2}$, respectively. The maximum performance can be obtained when the mass ratio of electrolyte is $30 \mathrm{wt} \%$ independent of the amount of Pt. In Fig. 5 (b), when the mass ratios of electrolyte are from 25 to $40 \mathrm{wt} \%$, the performances are almost the same, but in Fig. 5 (c), the cell performance strongly depends on the mass ratio of electrolyte.

\subsection{Thickness measurement}

Figure 6 (a) and (b) show the thickness of catalyst layers with various mass ratios of electrolyte as a function of the overall mass of a catalyst layer and the mass of $\mathrm{Pt} / \mathrm{C}$,

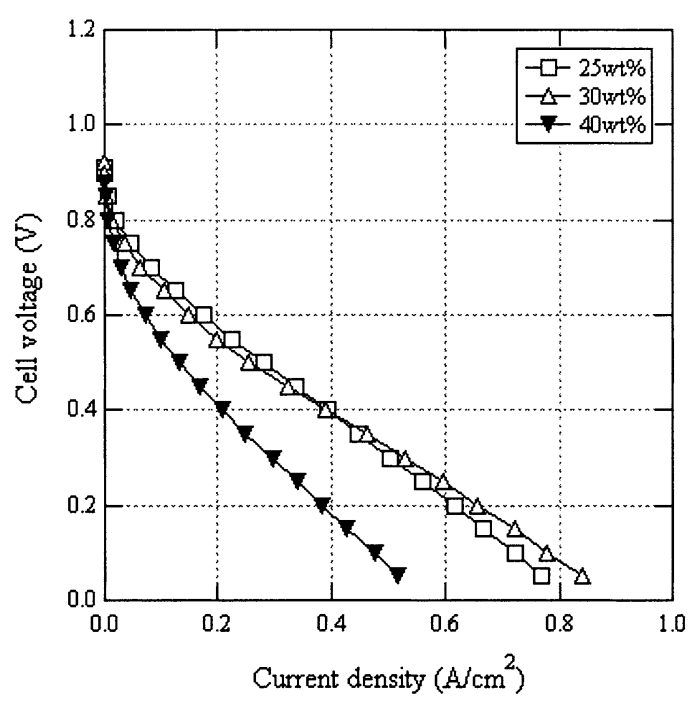

(a)

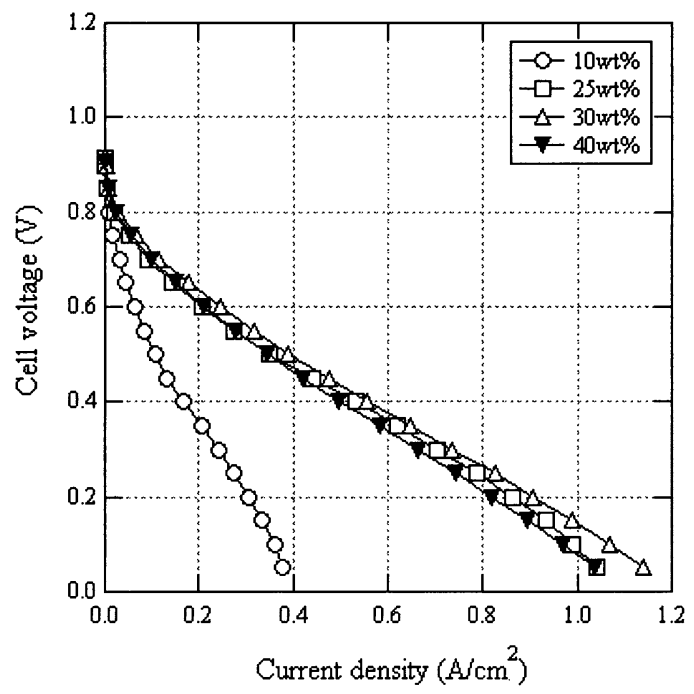

(b)

Fig. 5 (Continued)

respectively. The catalyst is $30 \% \mathrm{Pt}$ loading $\mathrm{Pt} / \mathrm{C}$. It is noted that the mass of $\mathrm{Pt} / \mathrm{C}$ is proportional to the overall mass of a catalyst layer if the mass ratio of electrolyte is constant. Figure 6(a) shows that the thickness of a catalyst layer is proportional to the overall mass of a catalyst layer, and the gradient is independent of the mass ratio of electrolyte. This result implies that the structure of a catalyst layer is not affected by the total amount of a catalyst layer.

In Fig. 6 (b), because the ratio of Pt loading on carbon particles is $30 \%$ in all the cases, the difference in thickness at the same mass of $\mathrm{Pt} / \mathrm{C}$ is due to the amount of electrolyte in a catalyst layer. The gradients of thickness with respect to the mass of $\mathrm{Pt} / \mathrm{C}$ for 40 and $50 \mathrm{wt} \%$ electrolyte are larger than those for 10, 20 and $30 \mathrm{wt} \%$ electrolyte and the gradients of the regression lines of 10, 25, 30, 40 and $50 \mathrm{wt} \%$ electrolyte are 17.6, 18.8, 17.7, 27.0 and 


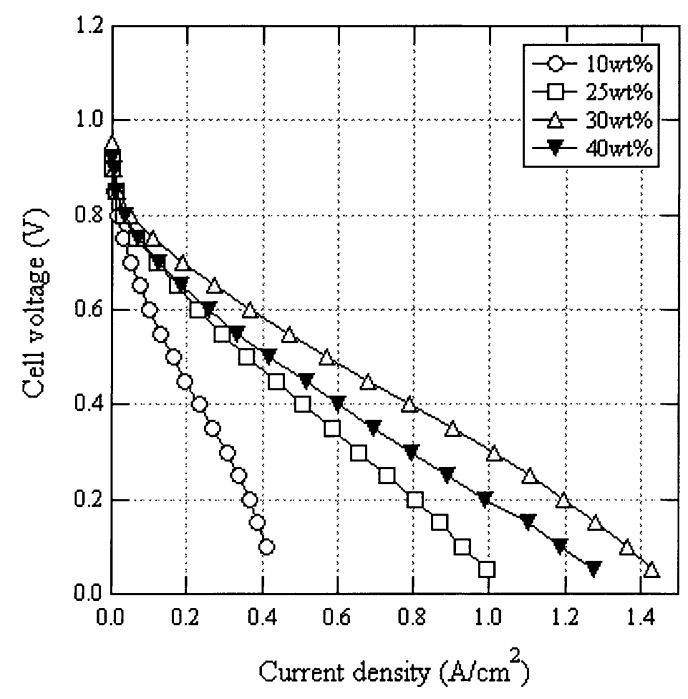

(c)

Fig. 5 Effect of the mass ratio of electrolyte in a catalyst layer on the polarization curves for three different amounts of Pt, (a) $0.07 \mathrm{mg} / \mathrm{cm}^{2}$, (b) $0.11 \mathrm{mg} / \mathrm{cm}^{2}$, (c) $0.21 \mathrm{mg} / \mathrm{cm}^{2}$. The catalyst is $30 \% \mathrm{Pt}$ loading $\mathrm{Pt} / \mathrm{C}$.

$25.5(\mu \mathrm{m}) /\left(\mathrm{mg} / \mathrm{cm}^{2}\right)$, respectively. This result implies that when the mass ratio of electrolyte in a catalyst layer is low, the electrolyte is mainly located between $\mathrm{Pt} / \mathrm{C}$ particles and it does not affect the thickness of a catalyst layer, on the other hand when the mass ratio of electrolyte is high, the whole amount of electrolyte cannot be located between particles, as a result the thickness of catalyst layers increases. To maximize catalyst utilization, the mass ratio of electrolyte in a catalyst layer should be about $30 \mathrm{wt} \%$. The results of the cell performance experiment also support this assumption.

\subsection{AFM imaging}

The surface of catalyst layers was examined using an AFM. Figure 7 (a) - (f) show the 3D images of the surface of catalyst layers and the cross sections in various conditions. In the image of the surface of $\mathrm{Pt} / \mathrm{C}$ particles (Fig. 7 (a)), fine roughness can be observed, and the height and the length are about a few hundred nm. It is commonly said that carbon particles cohere together and form the aggregate and agglomerate structures. The diameter of a Pt particle is only a few $\mathrm{nm}$ and the diameter of a carbon particle is $20-30 \mathrm{~nm}$. The AFM images suggests that the concavo-convex shapes in the surface image of $\mathrm{Pt} / \mathrm{C}$ are due to carbon particles and the aggregates of carbon particles because the diameter of a Pt particle is much smaller than the surface roughness. The surface shape does not depend on the overall mass of a catalyst layer, but it strongly depends on the mass ratio of electrolyte. The surface roughness decreases with increasing the mass ratio of electrolyte, and large undulation can be observed when the ratio of electrolyte in a catalyst layer is

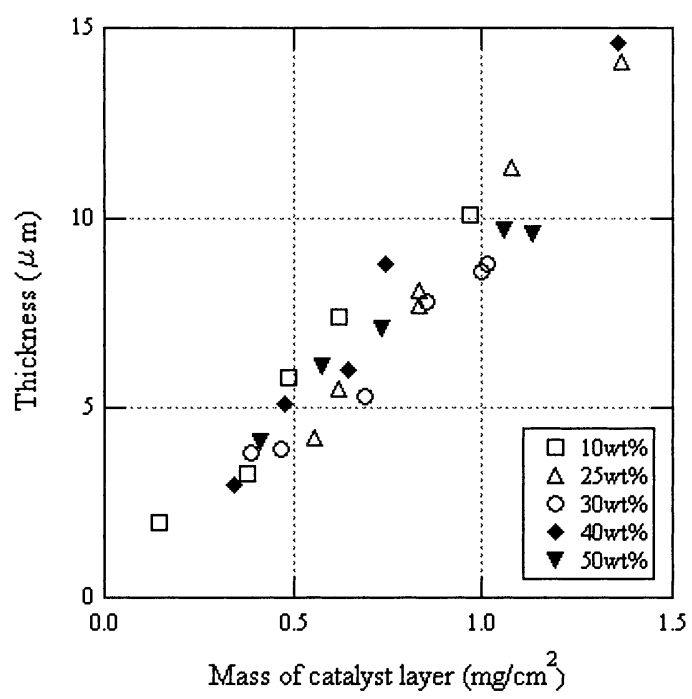

(a)

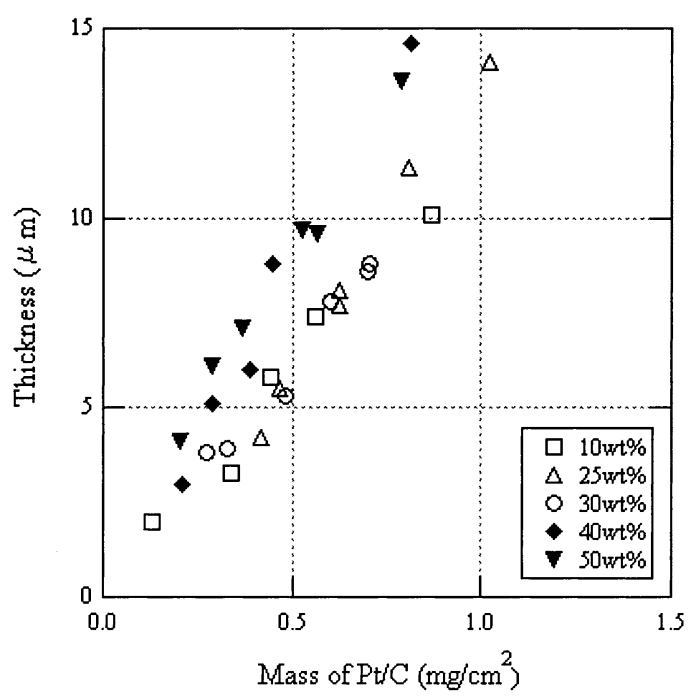

(b)

Fig. 6 Thickness of catalyst layers with various mass ratios of electrolyte (a) as a function of the overall mass of a catalyst layer, (b) as a function of the mass of $\mathrm{Pt} / \mathrm{C}$. The catalyst is $30 \% \mathrm{Pt}$ loading $\mathrm{Pt} / \mathrm{C}$.

40 wt $\%$ (Fig. 7 (f)). These AFM images implies that when the mass ratio of electrolyte is low, the fine roughness due to carbon particles is not influenced by the electrolyte, but when the mass ratio of electrolyte is high, the spaces between carbon particles are filled with the electrolyte, and the fine roughness disappears.

\section{Conclusions}

The effects of the overall mass of a catalyst layer and the mass ratio of electrolyte in a catalyst layer on the cell performance were investigated, and the thickness and the roughness of catalyst layers were measured with a micrometer and an atomic force microscope (AFM), respectively. The following conclusions could be drawn from 

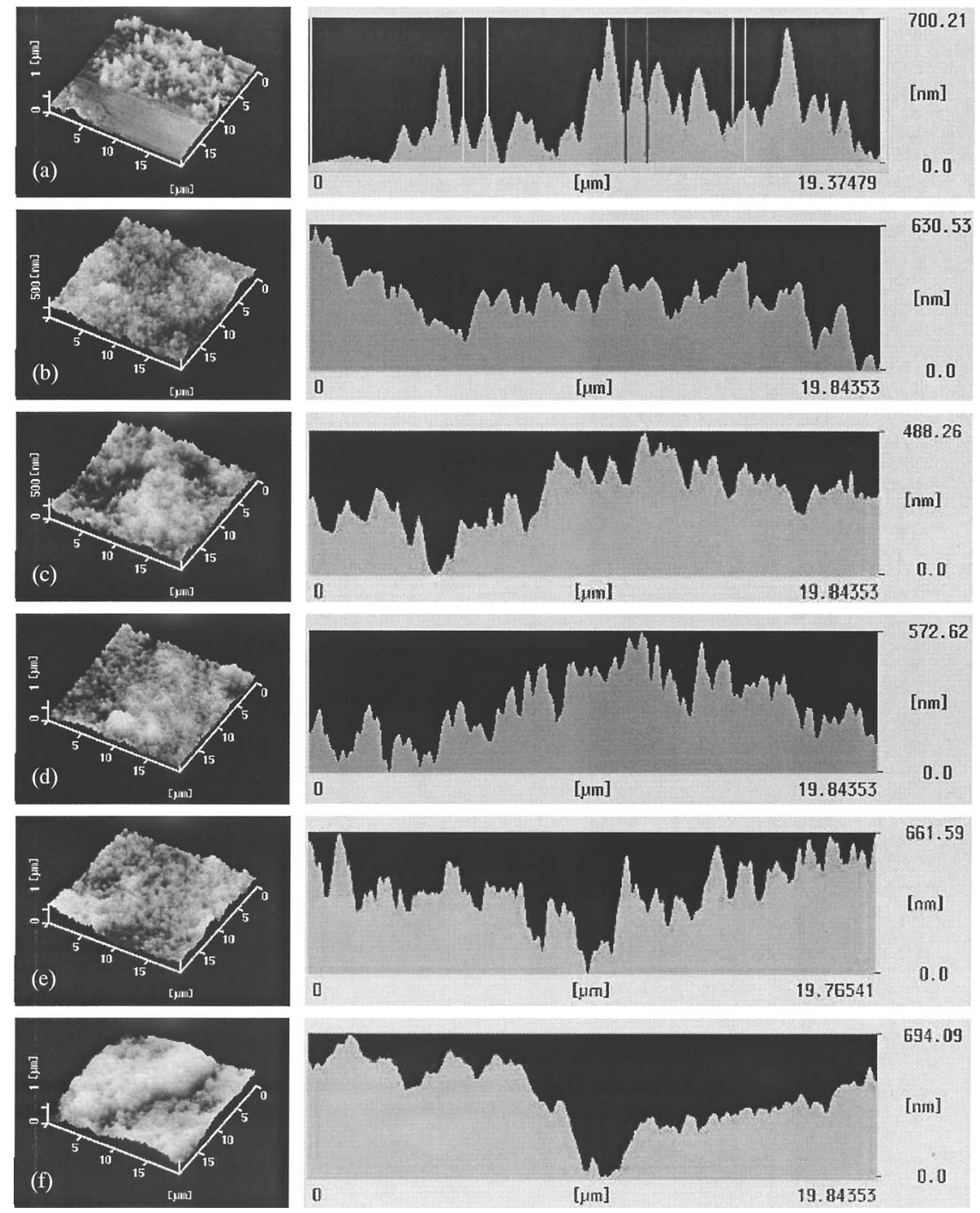

Fig. 7 AFM images of the surface of six different catalyst layers, (a) $\mathrm{Pt} / \mathrm{C}$ particles on a membrane, (b) $10 \mathrm{wt} \%$ electrolyte, $0.11 \mathrm{mg} / \mathrm{cm}^{2} \mathrm{Pt}$, (c) $25 \mathrm{wt} \%$ electrolyte, $0.07 \mathrm{mg} / \mathrm{cm}^{2}$ $\mathrm{Pt}$, (d) $25 \mathrm{wt} \%$ electrolyte, $0.11 \mathrm{mg} / \mathrm{cm}^{2} \mathrm{Pt}$, (e) $25 \mathrm{wt} \%$ electrolyte, $0.20 \mathrm{mg} / \mathrm{cm}^{2} \mathrm{Pt}$, (f) $40 \mathrm{wt} \%$ electrolyte, $0.11 \mathrm{mg} / \mathrm{cm}^{2} \mathrm{Pt}$. The catalyst is $30 \% \mathrm{Pt}$ loading $\mathrm{Pt} / \mathrm{C}$.

this study.

1. At a fixed composition, there is an optimum mass of a catalyst layer for the cell performance. As the mass of a catalyst layer increases, the total area of catalyst sites increases, but three criteria for a catalyst site, that is, proton access, gas access, and electronic path continuity, deteriorate. In the small current density region, the former is critical for the cell performance. But in the large current density region, the latter is more important.

2. At a fixed mass of catalyst layer, there is an optimum mass ratio of electrolyte for the cell performance. The value is independent of the mass of a catalyst layer.

3. The polarization curves strongly depend on the mass of a catalyst layer and the mass ratio of electrolyte particularly when both of them are large.

4. The measurement of the thickness and roughness of a catalyst layer suggests that the structure of a catalyst layer is influenced by the mass ratio of electrolyte, not by the overall mass of a catalyst layer. The structure of a catalyst layer changes significantly at the optimum mass ratio of electrolyte for the cell performance.

\section{References}

( 1 ) Ticianelli, E.A., Derouin, C.R., Redondo, A. and Srinivasan, S., Methods to Advance Technology of ProtonExchange Membrane Fuel-Cells, J. Electrochem. Soc., Vol.135 (1988), pp.2209-2214.

( 2 ) Wilson, M.S. and Gottesfeld, S., Thin-Film Catalyst Layers for Polymer Electrolyte Fuel Cell Electrodes, J. Appl. Electrochem., Vol.22 (1992), pp.1-7.

( 3 ) Lee, S.J., Mukerjee, S., McBreen, J., Rho, Y.W., Kho, Y.T. and Lee, T.H., Effects of Nafion Impregnation on Performance of PEMFC Electrodes, Electrochimica Acta, Vol.43 (1998), pp.3693-3701. 
( 4 ) Uchida, M., Aoyama, Y., Nobuo, E. and Ohta, A., New Preparation Method for Polymer Electrolyte Fuel Cells, J. Electrochem. Soc., Vol.142 (1995), pp.463-468.

( 5 ) Passalacqua, E., Lufrano, F., Squadrito, G., Patti, A. and Giorgi, L., Nafion Content in the Catalyst Layer of Polymer Electrolyte Fuel Cells: Effects on Structure and Performance, Electrochimica Acta, Vol.46 (2001), pp.799-805.
( 6 ) Lee, W.K., Ho, C.H., Zee, J.W.V. and Murthy, M., The Effects of Compression and Gas Diffusion Layers on the Performace of a PEM Fuel Cell, J. Power Sources, Vol.84 (1999), pp.45-51.

( 7 ) Wakizoe, M., Velev, O.A. and Srinivasan, S., Analysis of Proton Exchange Membrane Fuel Cell Performance with Alternate Membranes, Electrochimica Acta, Vol.40 (1995), pp.335-344. 